\title{
Development of a New Method for Bioassay of Allelopathy Using Protoplasts of a Leguminous Plant Mucuna pruriens With a High Content of the Allelochemical L-DOPA
}

\author{
Hamako Sasamoto $^{1,2}$, Tomoka Murashige-Baba ${ }^{1}$, Aya Inoue ${ }^{1}$, Toshiko Sato ${ }^{1}$, Shinji Hayashi ${ }^{1}$ \& Ai Hasegawa ${ }^{1}$ \\ ${ }^{1}$ Graduate School of Environment and Information Sciences, Yokohama National University, Yokohama, Japan \\ ${ }^{2}$ Faculty of Environment and Information Sciences, Yokohama National University, Yokohama, Japan \\ Correspondence: Hamako Sasamoto, Faculty of Environment and Information Sciences, Yokohama National \\ University, Yokohama, 240-8501, Japan. Tel: 81-45-339-4414. E-mail: sasamoto@ynu.ac.jp
}

Received: April 24, 2013 Accepted: May 20, 2013 Online Published: May 28, 2013

doi:10.5539/jps.v2n2p71 URL: http://dx.doi.org/10.5539/jps.v2n2p71

\begin{abstract}
To study allelopathy at the cellular level, we established a new bioassay method using protoplasts from etiolated leaves of a leguminous plant, Mucuna pruriens, which contains a large amount of L-3,4-dihydroxyphenylalanine (L-DOPA) and protoplasts prepared from cotyledons, leaves or roots of Lactuca sativa (lettuce) grown in an axenic condition. The bioassay was performed using 96 multi-well culture plates and required only a small volume of medium, $50 \mu \mathrm{L}$, per well. For the mixed culture of Mucuna and recipient lettuce protoplast, the optimum condition was Murashige and Skoog's basal medium, containing $1 \mu \mathrm{M}$ of 2,4-dichlorophenoxyacetic acid, $5 \mu \mathrm{M}$ of benzyladenine and $0.4 \mathrm{M}$ mannitol solution. The inhibitory effect of $M$. pruriens protoplasts was found to vary with the density of the recipient $L$. sativa protoplasts. The $M$. pruriens protoplasts had no effect on the division of protoplasts from suspension cells of Oryza sativa. These results were in agreement with those obtained by the conventional plant box method. Our study offered a novel in vitro assay method, which will be widely applicable to study allelopathy of various plants on lettuce and also for quantitative studies between plant species under different culture conditions in order to simulate the possible future environmental risk.
\end{abstract}

Keywords: allelopathy, bioassay method, Lactuca sativa, Leguminosae, L-DOPA, Mucuna pruriens, Oryza sativa, protoplast culture

\section{Introduction}

Both plant tissues and callus cultures of Mucuna pruriens var. utilis cv. Hassjoo (previously known as Stizolobium hassjoo) contain a large amount of 3, 4-dihydroxyphenylalanine (L-DOPA) which is used in the treatment of Parkinson's disease though its content in the latter is smaller than the former (Obata-Sasamoto et al., 1981). This species is also grown as a food crop and a cover crop plant (Jorge et al., 2007). M. pruriens is cultivated near Gramineae crops such as rice and corn in environment-friendly agriculture to enhance crop productivity. This is most likely due to additional N-nutrient supply to crops and the reduction of weed growth, which is related to its allelopathic activity caused by high content of L-DOPA (Fujii, 2003; Fujii et al., 2007). Allelopathic acitivities of the intact root of many plants on lettuce germination have been assayed by the in vitro 'plant box method', and M. pruriens was found to be one of the strongest allelopathic plants (Fujii et al., 2007).

Protoplasts of M. pruriens had been isolated from etiolated leaves (Murashige et al., 2004); however, cultures were unstable because protoplast isolation is occasionally inhibited by melanin formation from L-DOPA during enzymatic treatment for cell wall removal. The techniques we designed in this report for plant preparation and protoplast isolation produced stable cultures without melanin formation and enabled further bioassay.

The lettuce germination assay method is used in the 'plant box method' for allelopathy (Fujii et al., 2007). Therefore, we searched for the conditions optimum for the protoplast culture and cell division of Mucuna and lettuce. First, we examined the effects of basal media [Murashige and Skoog's (Murashige \& Skoog, 1962), ammonium nitrate-free MS (MMS)]; plant growth regulators [2, 4-dichlorophenoxyacetic acid (2, 4-D), benzyladenine (BA), gibberellic acid $\left(\mathrm{GA}_{3}\right)$, and abscisic acid (ABA)], sugars, osmotic conditions (mannitol, sorbitol), and cell density, on the growth of protoplast cultures. Then, we examined the effects of M. pruriens protoplasts obtained from etiolated leaves on the cell division of lettuce protoplasts. Furthermore, since the plant 
box method and field test revealed no inhibitory effects of Mucuna on Oryza sativa (rice) (Fujii et al., 2007), we examined the effects of mixed culture with Mucuna and rice. We also examined whether L-DOPA had an allelopathc activity on protoplast cultures of lettuce and rice. Advantages of the new protoplast method are discussed.

\section{Method}

\subsection{Plant Preparation}

Seeds of Mucuna pruriens were treated with $0.2-0.5 \%$ of a neutral detergent Mamma-lemon (Lion Corporation), treated with $5 \% \mathrm{NaClO}$ solution for $10 \mathrm{~min}$ and washed with tap water. A small portion of the seed coat was cut and the seeds were imbibed for several hrs in tap water. After removal of the seed coat, they were planted in vermiculite (autoclaved at $121{ }^{\circ} \mathrm{C}$ for $20 \mathrm{~min}$ ) in a clean pot, watered and incubated at $25^{\circ} \mathrm{C}$ in a dark box with three layers of corrugated paper on the top to supply dim light. After 2 or 3 weeks of incubation, etiolated leaves were used for protoplast isolation.

Lactuca sativa (lettuce) seeds 'Great Lakes 366' were sterilized with $1.5 \% \mathrm{NaClO}$ solution for 15 min and washed with autoclaved water three times. They were cultured on $0.8 \%$ agar medium for 10-20 days in the light condition for cotyledons and leaves, and 4 days for roots in the dark or the light.

A suspension culture of Oryza sativa (rice) (Oc strain) was obtained from Riken Bio-Resource Center Japan. They were sub-cultured in MS medium containing $4.5 \mu \mathrm{M}$ of 2, 4-D and 3\% sucrose.

\subsection{Protoplast Isolation}

Etiolated leaves of M. pruriens were sterilized with $1 \% \mathrm{NaClO}$ solution for $10 \mathrm{~min}$ and washed with autoclaved water three times. Leaf sections were treated for $18 \mathrm{hrs}$ with $0.4 \mathrm{M}$ mannitol solution containing $1 \%$ each of Cellulase RS (Yakult Honsha), Hemicellulase (H-2125, Sigma) and Macerozyme R-10 (Yakult) in a flask or in wells of a 24-well culture plate under a sterile condition. The optimum enzyme combination was previously determined from 24 combinations of six enzymes (Sasamoto et al., 1997). After passing through a $42 \mu \mathrm{m}$ sized nylon mesh, protoplasts were purified by washing three times with the mannitol solution followed by centrifugation at $190 \mathrm{~g}(1000 \mathrm{rpm})$ for $5 \mathrm{~min}$.

Lettuce leaf protoplast isolation was performed using 1\% each of Cellulase RS and Macerozyme R-10 in $0.4 \mathrm{M}$ mannitol solution. Protoplasts were passed through a $42 \mu \mathrm{m}$ mesh and purified by centrifugation at $120 \mathrm{~g}$ ( 800 rpm) for 5 min. Root protoplast isolation was performed using 1\% each of Cellulase RS, Driselase 20 (Kyowa Hakko Kogyo) and $0.2 \%$ of Pectolyase Y-23 (Seishin) in $0.4 \mathrm{M}$ mannitol solution. Protoplasts were passed through a $42-63 \mu \mathrm{m}$ sized mesh and purified by centrifugation at $760 \mathrm{~g}(2000 \mathrm{rpm})$ for $5 \mathrm{~min}$. Rice protoplasts were isolated by $1 \%$ each of Cellulase RS and Macerozyme R-10 in $0.6 \mathrm{M}$ mannitol solution.

All of the procedures were performed at room temperature.

\subsection{Protoplast Culture}

Protoplast suspensions, $5 \mu \mathrm{L}$ each, were put into $50 \mu \mathrm{L}$ of liquid medium in a 96-well plastic culture plate (Falcon No. 3075); $100 \mu \mathrm{L}$ of autoclaved pure water (Milipore Elix3) was added "between" the wells and the plate was tightly sealed with two layers of Parafilm ${ }^{\mathrm{R}}$. The protoplasts were cultured at $28{ }^{\circ} \mathrm{C}$ in a humid incubator $\left(\mathrm{CO}_{2}\right.$-incubator without the supply of $\mathrm{CO}_{2}$, APC-30DR, ASTEC Co. Ltd.). Numbers of enlarged- and divided- protoplasts were counted periodically (1-6 weeks) under an inverted microscope (Olympus CK40 or IX71).

Effects of basal media [MS (Murashige \& Skoog, 1962), ammonium nitrate-free MS: MMS], different levels (0, $0.1,1,10 \mu \mathrm{M})$ of plant growth regulators [2, 4-dichlorophenoxyacetic acid (2, 4-D), benzyladenine (BA), gibberellic acid $\left(\mathrm{GA}_{3}\right)$, and abscisic acid (ABA)], osmotic sugars (mannitol, sorbitol and glucose), and cell density, were investigated. All cultures contained 3\% sucrose as the nutrient carbon source. The cell density ranged from 5 to $600 \times 10^{3} / \mathrm{mL}$.

Mixed cultures of Mucuna protoplasts with lettuce or rice were performed in MS medium containing $1 \mu \mathrm{M}$ of 2, 4-D and $5 \mu \mathrm{M}$ of BA and 0.4 M mannitol. L-DOPA instead of Mucuna protoplasts was put in the above medium for protoplast cultures of lettuce and rice. MMS medium containing $1 \mu \mathrm{M}$ of 2, 4-D and $0.1 \mu \mathrm{M}$ of BA was also used.

\subsection{Data Description}

Growth of protoplasts was described as the numbers of enlarged ( $>50 \mu \mathrm{m}$ diameter) and divided protoplasts or colonies in a well. All data were averages of at least two wells and standard errors are shown in the figures. In 
several figures, data were described as the percentage of the control without M. pruriens protoplasts or L-DOPA. All experiments were repeated more than once. Plating efficiency was described as the percentage of divided protoplasts by the initial number of plated protoplasts.

\section{Results and Discussion}

\subsection{Protoplast Isolation of M. pruriens}

Pre-treatment of seeds with high concentration of $\mathrm{NaClO}$ and incubation at clean conditions used in this report, much reduced occasional microbial contamination of plant materials and improved efficiency of axenic protoplast isolation compared to that of previous work (Murashige et al., 2004). Viable protoplasts of $M$. pruriens could be obtained more efficiently using the 24-well culture plate instead of a flask method of previous work (Sasamoto et al., 2006). Black melanin formation by L-DOPA, which large amount reduced viability of protoplasts, did not occur during the enzymatic treatment of the small amount of leaf tissue in each separate well, though light red color of dopaquinone was observed. This method will be useful for the isolation of protoplasts from tissues of other plants containing high levels of allelochemicals or phenolics.

\subsection{Protoplast Culture of M. pruriens}

The number of cell divisions and enlarged cells ( $>50 \mu \mathrm{m}$ diameter) were counted under an inverted microscope after 7 days of culture in both MS and MMS media (Figure 1). During the first two weeks of culture, cell divisions were observed in both MS (Figure 2a) and MMS (Figure 2b) medium. Thus, either medium could be used for examining allelopathy of protoplasts at the early stage of culture, i.e., within one or two weeks. However, after 6 weeks of culture, large colony formation (Figure 2c) continued only in the MS basal medium containing $1 \mu \mathrm{M}$ of 2, 4-D and $5 \mu \mathrm{M}$ of BA. After transfer to the same composition medium without the osmoticum, green calli were successfully subcultured under a light condition (data not shown). Early colony formation was heavily dependent on cell density (Figure 3); no colony proliferation was observed at a cell density of less than $2 \times 10^{5} / \mathrm{mL}$. Figure 4 shows the effects of various combinations of 2, 4-D and BA on cell division; 0.1 and $1 \mu \mathrm{M}$ of 2, 4-D and $1-10 \mu \mathrm{M}$ of BA were optimal at $2 \times 10^{5} / \mathrm{mL}$. Previously, in callus culture of $M$. pruriens, different hormonal concentrations ( $5 \mu \mathrm{M}$ of 2, 4-D and $0.5 \mu \mathrm{M}$ of BA) in MS basal medium were used (Obata-Sasamoto et al., 1981). Mucuna protoplasts preferred MS and KM-8p (Kao \& Michayluk, 1975) than MMS as basal medium, and glucose and mannitol gave better results than sorbitol at high cell densities: $2 \mathrm{x}$ $10^{5} / \mathrm{mL}$ or more (Murashige et al., 2004; Sasamoto et al., 2005). KM-8p medium, in which glucose was the main sugar component, was originally used for the culture of protoplasts of leguminous plant Vicia species. Figure 5a shows the inhibition of colony formation in Mucuna protoplast culture by ABA in the MS basal medium containing $1 \mu \mathrm{M}$ of 2, 4-D and $5 \mu \mathrm{M}$ of BA. In contrast, $\mathrm{GA}_{3}$ had no inhibitory effect in Mucuna (Figure $5 b)$. The inhibitory effect of ABA on cell growth is commonly observed in plant cell cultures (Sasamoto et al., 1995).

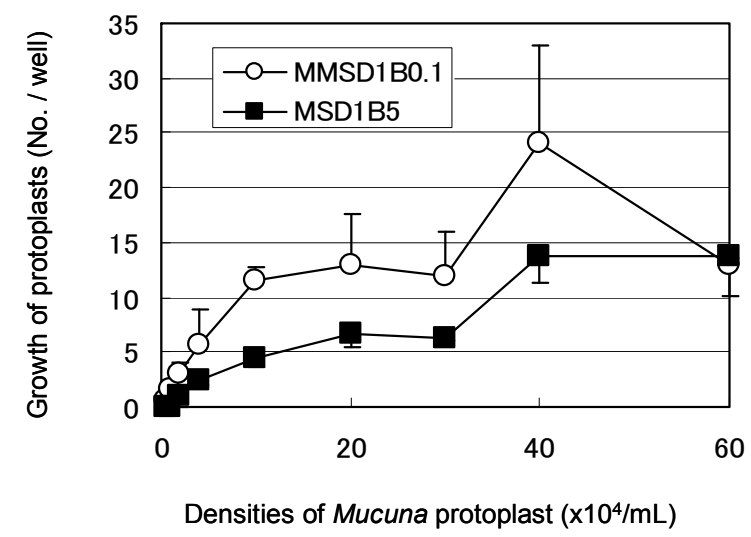

Figure 1. Effects of density on growth of $M$. pruriens protoplasts in MS basal medium containing $1 \mu \mathrm{M}$ of 2, 4-D and $5 \mu \mathrm{M}$ of BA or in MMS basal medium containing $1 \mu \mathrm{M}$ of 2, 4-D and $0.1 \mu \mathrm{M}$ of BA. Divided- and enlargedprotoplasts larger than $50 \mu \mathrm{m}$ diameter were counted after 7 days of culture. Both media contained $3 \%$ sucrose and 0.4 M mannitol 


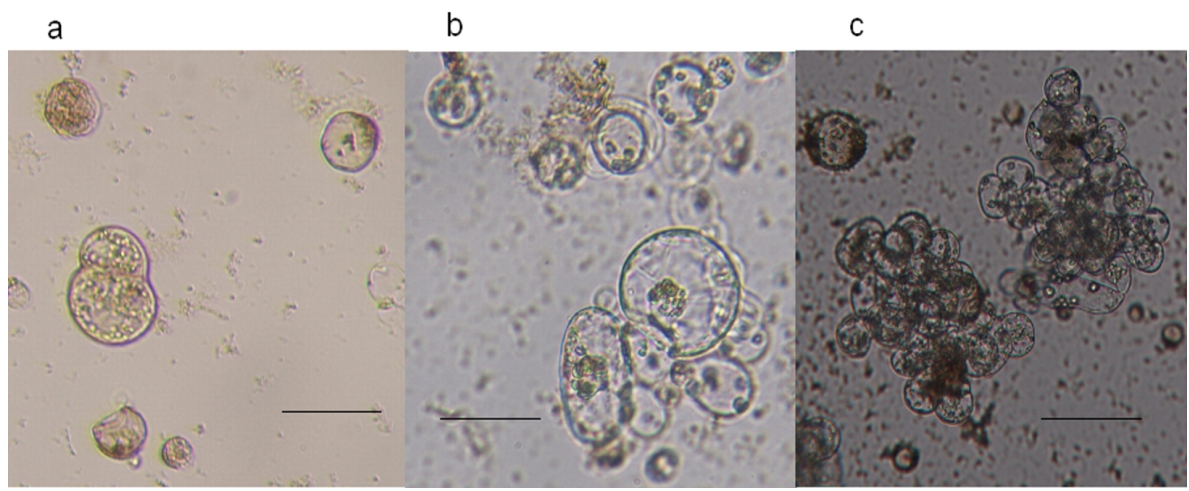

Figure 2. Photographs of divided protoplasts $(\mathrm{a}, \mathrm{b})$ after 15 days of culture, and large colonies (c) after 6 weeks of culture of $M$. pruriens protoplasts. a, c: in MS basal medium; b: in MMS basal medium, containing $1 \mu \mathrm{M}$ of 2, 4-D and $5 \mu \mathrm{M}$ of BA, $3 \%$ sucrose, $0.4 \mathrm{M}$ mannitol. Bar $=50 \mu \mathrm{m}(\mathrm{a}, \mathrm{b})$ and $100 \mu \mathrm{m}(\mathrm{c})$

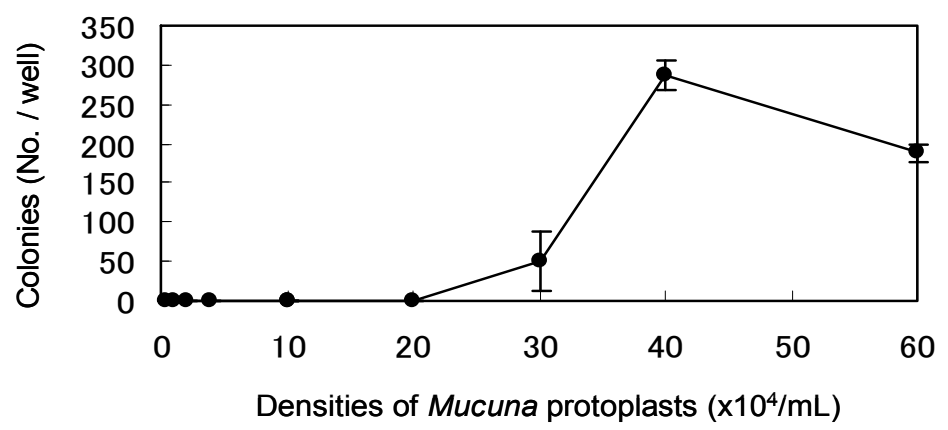

Figure 3. Effects of densities on large colony formation of $M$. pruriens protoplasts after 42 days of culture. Medium was MS containing $1 \mu \mathrm{M}$ of $2,4-\mathrm{D}$ and $5 \mu \mathrm{M}$ of BA, $3 \%$ sucrose and $0.4 \mathrm{M}$ mannitol

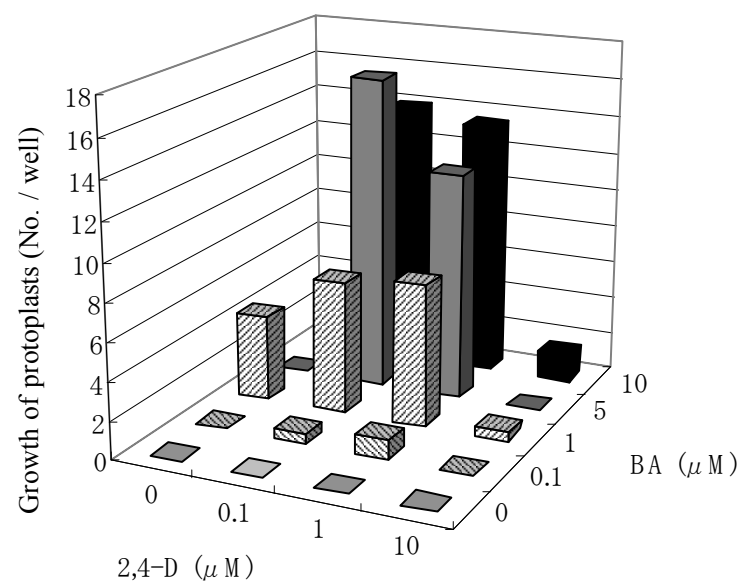

Figure 4. Effects of 2, 4-D and BA on growth (division) of $M$. pruriens protoplasts after 7 days of culture. Medium was MS basal medium containing 3\% sucrose and $0.4 \mathrm{M}$ glucose. Density was $2 \times 10^{5} / \mathrm{mL}$ 
a

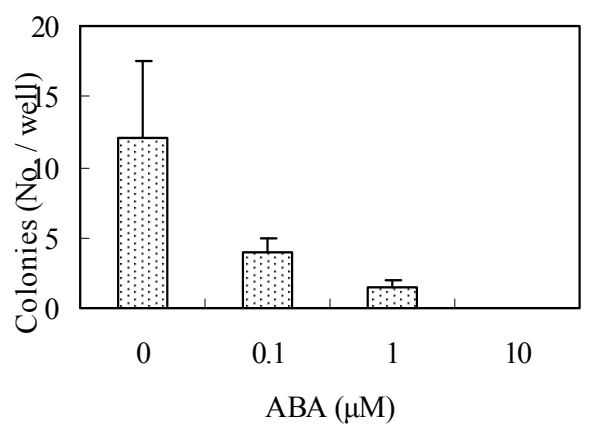

$\mathrm{b}$

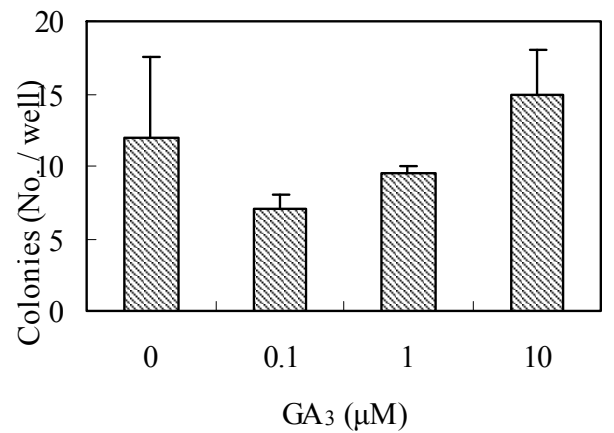

Figure 5. Effects of $\mathrm{ABA}$ (a) and $\mathrm{GA}_{3}$ (b) on growth (division) of $M$. pruriens protoplasts at $2 \times 10^{5} / \mathrm{mL}$ after 7 days of culture in MS basal medium containing $1 \mu \mathrm{M}$ of 2, 4-D and $5 \mu \mathrm{M}$ of BA, $3 \%$ sucrose and $0.4 \mathrm{M}$ glucose

\subsection{Protoplast Culture of Lettuce}

In contrast to Mucuna protoplasts, KM-8p basal medium and glucose inhibited the growth of protoplasts of lettuce at lower cell densities (Sasamoto et al., 2005). Protoplasts of the lettuce cultivar 'Great lakes 366', which is commonly used in the bioassay of allelopathy, were found to grow better in MMS medium than in MS medium, and to grow well in the presence of plant growth regulators, 2, 4-D and BA, at various concentrations and at various cell densities, but not in cytokinin-free medium (Figure 6a, Sasamoto et al., 2005; Sasamoto et al., 2006). These observations are consistent with the report on different cultivars in a medium with a low ammonium nitrate content than in MS medium (Nishio et al., 1988). ABA increased colony formation (Figure 6b), though $\mathrm{GA}_{3}$ inhibited the colony formation in lettuce leaf protoplasts (Figure 6c), while the reverse was observed in M. pruriens protoplasts (Figure 5a and 5b).
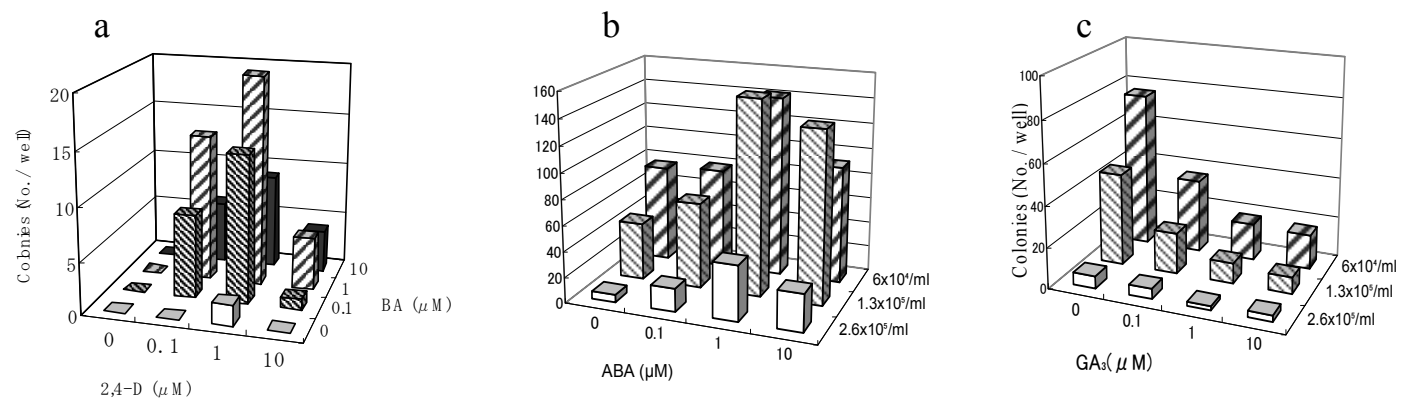

Figure 6. Effects of 2, 4-D and BA (a), ABA (b) and $\mathrm{GA}_{3}$ (c) on colony formation in leaf protoplast cultures of lettuce in MMS basal medium containing 3\% sucrose, $0.4 \mathrm{M}$ mannitol after 7 days of culture. a: Density was 2.5 x $10^{5} / \mathrm{mL}$. b, c: Medium contains $0.1 \mu \mathrm{M}$ of 2,4-D and $10 \mu \mathrm{M}$ of BA. Densities were $6 \times 10^{4} / \mathrm{mL}, 1.3 \times 10^{5} / \mathrm{mL}$ and $2.6 \times 10^{5} / \mathrm{mL}$

\subsection{Mixed Culture of Mucuna vs. Lettuce}

For the mixed culture of Mucuna and lettuce protoplasts, we used the MS basal medium containing $1 \mu \mathrm{M}$ of 2 , 4-D, $5 \mu \mathrm{M}$ of BA and $0.4 \mathrm{M}$ mannitol solution (Sasamoto et al., 2005), which was optimal for Mucuna protoplasts, but suboptimal for lettuce protoplast culture as described above. The effects of M. pruriens protoplasts obtained from etiolated leaves on the division of lettuce protoplasts were determined as the allelopathic activities of Mucuna on lettuce. At a low cell density of lettuce leaf protoplasts (less than $2 \times 10^{4} /$ $\mathrm{mL}$ ), the colony formation of the lettuce leaf protoplasts was stimulated by low concentrations of M. pruriens leaf protoplasts (Figure 7). In contrast, at high cell densities of lettuce leaf protoplasts $\left(10^{5} / \mathrm{mL}\right.$ or $\left.2 \times 10^{5} / \mathrm{mL}\right)$, addition of Mucuna leaf protoplasts inhibited the division of the lettuce leaf protoplasts (Figure 8). Numbers of colonies at zero control without Mucuna protoplast was 30 (at $10^{5} / \mathrm{mL}$ ) and 61 (at $2 \times 10^{5} / \mathrm{mL}$ ). Such an 
inhibitory effect of Mucuna on lettuce growth was also observed in MMS basal medium containing $1 \mu \mathrm{M}$ of 2 , 4-D and $0.1 \mu \mathrm{M}$ of BA and 0.4 M mannitol solution (data not shown).
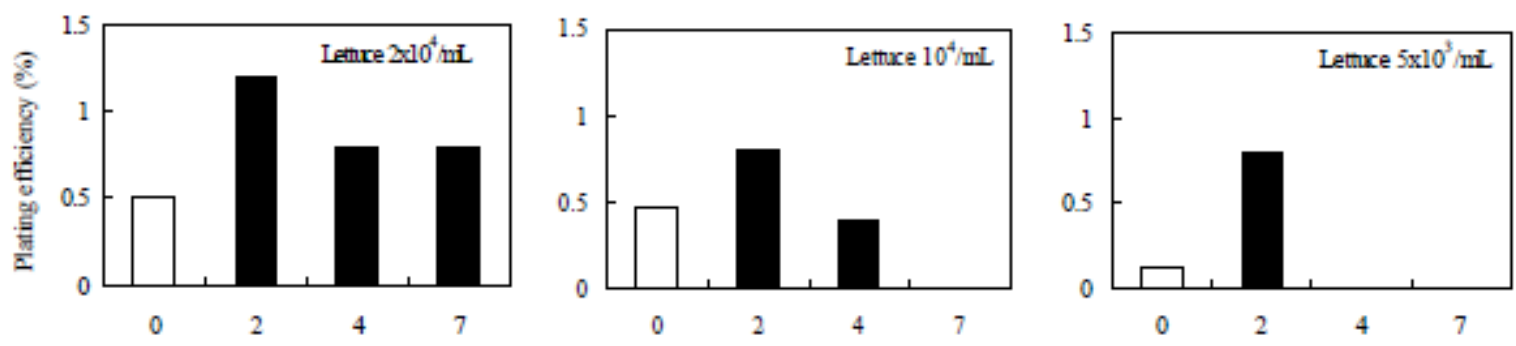

Densities of Mucuna protoplasts $\left(\mathrm{x} 10^{4} / \mathrm{mL}\right)$

Figure 7. Effects of $M$. pruriens protoplasts on leaf protoplast cultures of lettuce after 5 days of culture. Medium was MS containing $1 \mu \mathrm{M}$ of $2,4-\mathrm{D}$ and $5 \mu \mathrm{M}$ of BA, $3 \%$ sucrose and $0.4 \mathrm{M}$ mannitol. Plating efficiency was described as the $\%$ of divided protoplasts in a well

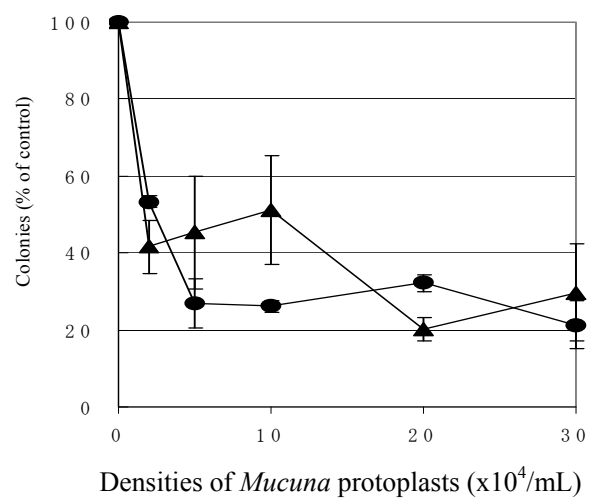

Figure 8. Effects of $M$. pruriens protoplasts on colony formation ( $\%$ of control) of lettuce leaf protoplasts at $10^{5} /$ $\mathrm{mL}$ (triangle) or $2 \times 10^{5} / \mathrm{mL}$ (circle) after 7 days of culture. Medium was the same as in Figure 7

Root protoplast division was also examined in MMS basal medium containing $1 \mu \mathrm{M}$ of 2 , 4-D and $0.1 \mu \mathrm{M}$ of BA, a hormonal condition optimal for large colony formation from lettuce root protoplasts (Sasamoto et al., 2006). At a lettuce root protoplast cell density of $2 \times 10^{4} / \mathrm{mL}$, addition of Mucuna inhibited cell division of lettuce root protoplasts after 15 days of culture (Figure 9). As the protoplasts in the etiolated leaves of Mucuna are colorless, the difference of cell enlargement or division between lettuce root protoplasts was difficult to distinguish at early stage of culture. However, as the selected hormonal condition and the densities were not optimal for growth of Mucuna protoplasts (Figures 3 and 4), most of divisions of protoplasts shown in Figure 9 could be of lettuce root protoplasts'. If the color or the size of protoplasts of the recipient plant is readily distinguishable, root protoplasts could also be widely used for the allelopathy assay.

At a lettuce root protoplast cell density of $1 \sim 3 \times 10^{4} / \mathrm{mL}$, no stimulation was observed by the addition of low concentrations of Mucuna protoplasts which occurred in the mixed culture with lettuce leaf protoplasts at a low cell density (Figure 7). A clear inhibitory effect of Mucuna was observed in the culture of lettuce root protoplasts. In the 'plant box method', the root length or hypocotyl length of the lettuce seedlings are measured (Fujii et al., 2007). In some cases, a small transient increase in hypocotyl growth is observed, though root growth is inhibited by allelochemicals. Stimulation of growth of lettuce leaf protoplasts by low concentrations of M. pruriens protoplasts might be related to the phenomenon of non-root organs, which might reflect the difference of optimal effective concentrations of allelochemicals in different organs or the transport of some nutrients from growth-inhibited roots. Therfore, the mixed culture of protoplasts showed the same inhibitory effects of $M$. pruriens on lettuce as the plant box method. 


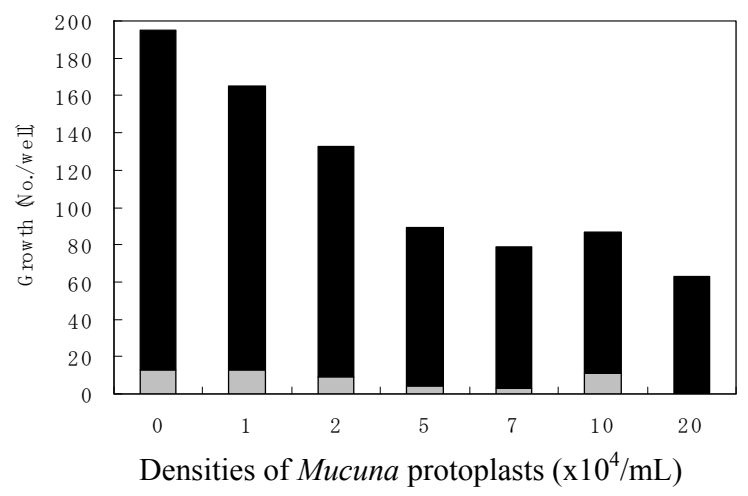

Figure 9. Effects of M. pruriens on growth of lettuce root protoplasts $\left(2 \times 10^{4} / \mathrm{mL}\right)$ after 15 days of culture. Black column shows division and light colored column shows enlargement of protoplasts. Medium was MMS containing $1 \mu \mathrm{M}$ of 2, 4-D and $0.1 \mu \mathrm{M}$ of BA, $3 \%$ sucrose, $0.4 \mathrm{M}$ mannitol

\subsection{Mixed Culture of Mucuna vs. Rice}

No clear stimulation or inhibition was observed when M. pruriens and rice suspension cell protoplasts were cultured together (Figure 10). This observation was similar to that obtained by the plant box method and field test (Fujii et al., 2007).

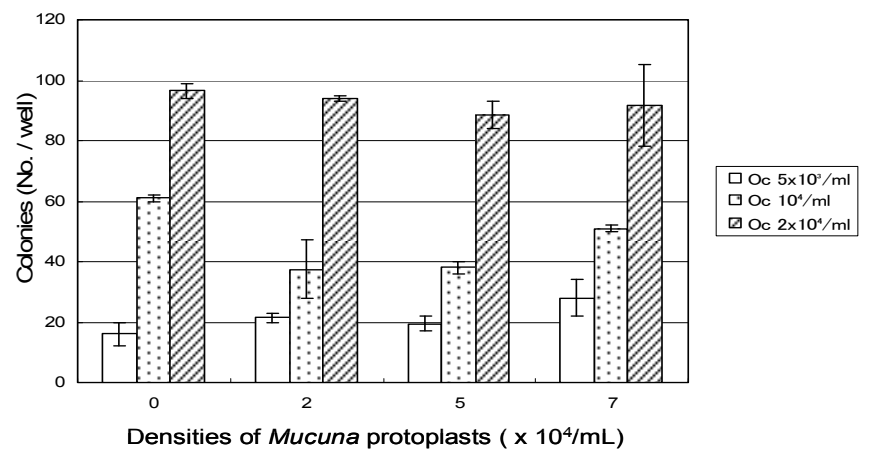

Figure 10. Effects of $M$. pruriens protoplasts on colony formation of rice suspension protoplasts in MS containing $1 \mu \mathrm{M}$ of 2, 4-D and $5 \mu \mathrm{M}$ of BA, $3 \%$ sucrose, $0.4 \mathrm{M}$ mannitol after 7 days of culture. Numbers of colonies with 2-5 cells were counted

\subsection{Effect of L-DOPA on Lettuce and Rice Protoplasts}

The inhibitory effects of protoplasts of M. pruriens on lettuce or rice protoplasts can be partly ascribed to the high L-DOPA content of the protoplasts of M. pruriens. The inhibitory effect on lettuce was 5-10 fold that on rice (Figure 11). This inhibitory effect was similar to that observed using the plant box method and field test (Fujii et al., 2007).

The L-DOPA content in callus was $0.14 \mu$ moles / $\mathrm{g}$ fresh weight at optimal hormonal condition for growth (Obata-Sasamoto et al., 1981), while at the suboptimal conditions for growth, the highest L-DOPA content in callus was $1 \mu$ moles / $g$ fresh weight (Obata-Sasamoto \& Komamine, 1983). The L-DOPA content of protoplasts from etiolated leaves of M. pruriens was reported to be 20 nmoles $/ 10^{6}$ protoplasts from amino acid analysis (Sato et al., 2007; Tsuchiya et al., 2011). This amount is calculated to be $5 \mathrm{mM}$ in the protoplast assuming that L-DOPA is distributed uniformly in a protoplast. When all the L-DOPA in the protoplast is secreted, the L-DOPA concentration at a cell density of $2 \times 10^{5} / \mathrm{mL}$ in a well of a 96-well microplate would be $4 \mu \mathrm{M}$. This might partly explain the inhibitory effect on lettuce and non-inhibitory effect on rice protoplasts. However, as the inhibitory effect of $M$. pruriens protoplasts was observed at a much lower cell density, L-DOPA might not be the only sole cause of the allelopathic acitivity of $M$. pruriens and different mechanisms of inhibition of growth by this compound must be considered. Other compounds including $\mathrm{ABA}$ and $\mathrm{GA}_{3}$ may also be involved since the effects of these compounds on cell division in M. pruriens were different (reverse) from those in lettuce. Since a high 
cell density was needed for the colony formation, the protoplasts of $M$. pruriens appeared tolerant to L-DOPA. Leaf protoplasts of lettuce are relatively easy to obtain and since they are green, the leaf protoplasts are easy to distinguish, in mixed culture with colorless suspension cells.

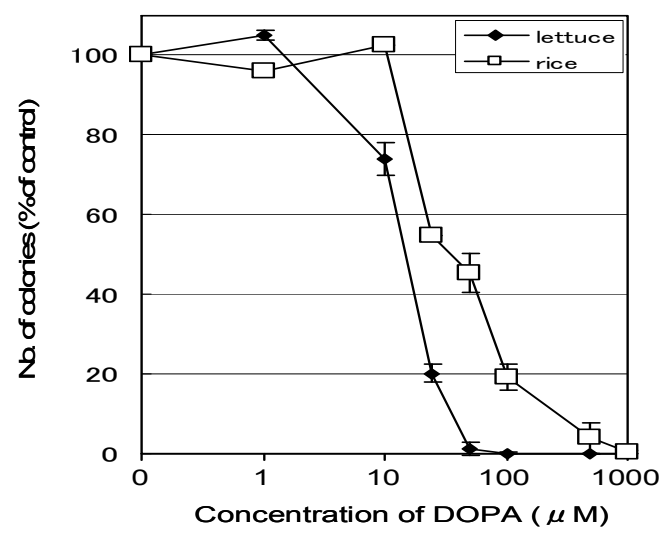

Figure 11. Effects of L-DOPA on colony formation of lettuce and rice protoplasts at $5 \times 10^{4} / \mathrm{mL}$. Numbers of colonies with more than 5 cells, after 7 days of culture, are shown as the $\%$ of the control without addition of L-DOPA

\subsection{Protoplast Method Compared to Plant Box Method for Bioassay of Allelopathy}

Allelopathic acitivities of the intact root of many plants on lettuce germination have been assayed by the in vitro 'plant box method', and M. pruriens was found to be one of the strongest allelopathic plants (Fujii et al., 2007). The 'plant box method' requires small seedlings as test plants, and test seedlings of tree species can be difficult to obtain. Furthermore, the direct allelopathic relation between different plant species is difficult to determine using this method. In this report, we established a new bioassay method of allelopathy by studying its effects on cell division of lettuce protoplasts. This allows cells to interact directly and the allelopathic effects on the recipient protoplasts can be easily distinguished. As protoplasts, without a protecting cell wall, are considered to be under a stressful condition, e.g., high osmotic environment, more allelopathic substances might be secreted than normal cells. This protoplast method is a simple system because the protoplasts affected can be counted under an inverted microscope within one week of culture and quantitative investigation is possible using 96 -well microplates. The $M$. pruriens protoplasts had no effect on the division of protoplasts from rice suspension cells. This phenomenon was the same as that observed by the plant box method. Our study offered a novel in vitro assay method, which will be widely applicable to study allelopathy of various plants on lettuce and also for quantitative studies between different plant species. Another advantage of this method is that it can be applied under different culture conditions, e.g., high and low temperatures or different nutritional conditions, in order to simulate the possible future environmental risk. Measurement of possible impact of invasive species and genetically modified organisms (GMO) etc., at an early stage is important for much reduction of the risk of these plants. The protoplast method can be used to study the allelopathy of such plants and furthermore, to investigate the mechanism of the allelopathy at cellular level.

In this report, we used a herbaceous leguminous plant. We are also exploring the allelopathy of mangrove plants, which are distributed in tropical and subtropical brackish coastal regions and the possibility of using their salt-tolerant characteristics to introduce to GMO and micropropagation. We tried a "protoplast method" using several mangrove tree species and have performed bioassays of the allelopathic activities on lettuce protoplasts (Hasegawa et al., 2010; Inoue et al., 2010).

\section{Conclusion}

Protoplast isolation method was improved for etiolated leaves of a leguminous plant, Mucuna pruriens, which contains a large amount of the allelochemical L-DOPA. Effects of basal media, i.e. MS and MMS; plant growth regulators, i.e. 2, 4-D, $\mathrm{BA}, \mathrm{ABA}$ and $\mathrm{GA}_{3}$; protoplasts densities, on $M$. pruriens protoplast culture were investigated and compared to those on lettuce protoplasts culture. Then, to study allelopathy at the cellular level, we established a new bioassay method, i.e. mixed culture of $M$. pruriens protoplasts and recipient protoplasts from leaves or roots of lettuce grown in an axenic condition. The bioassay was performed using 96 multi-well culture plates and required only a small volume of medium, $50 \mu \mathrm{L}$, per well. For the mixed culture of Mucuna 
and recipient lettuce leaf protoplasts, the optimum condition selected was MS basal medium, containing $1 \mu \mathrm{M}$ of 2, 4-D, $5 \mu \mathrm{M}$ of BA and $0.4 \mathrm{M}$ mannitol solution. The inhibitory effect of $M$. pruriens protoplasts was found to vary with the density of the recipient lettuce protoplasts. In contrast, the $M$. pruriens protoplasts had no effect on the division of protoplasts from suspension cells of Oryza sativa. These results were in agreement with those obtained by the conventional plant box method. Our study offered a novel in vitro assay method, which will be widely applicable to study allelopathy at the cellular level of various plants on lettuce and also for quantitative studies between plant species under different culture conditions in order to simulate the possible future environmental risk.

\section{Acknowledgements}

We would like to thank Prof. E. C. Yeung of the University of Calgary for his valuable suggestions on the manuscript.

\section{References}

Fujii, Y. (2003). Allelopathy in the natural and agricultural ecosystems and isolation of potent allelochemicals from Velvet bean (Mucuna pruriens) and Hairy vetch (Vicia villosa). Biological Sciences in Space, 17, 1-8. http://dx.doi.org/10.2187/bss.17.6

Fujii, Y., Pariasca, D., Shibuya, T., Yasuda, T., Kahn, B., \& Waller, G. R. (2007). Plant Box Method: A specific bioassay to evaluate allelopathy through root exudates. In Y. Fujii \& S. Hiradate (Eds.), Allelopathy new concepts and methodology (pp. 39-56). Science Publishers, Inc. Enfield, NH, USA.

Hasegawa, A., Tsuchiya, S., Inoue, A., \& Sasamoto, H. (2010). Salt tolerancy and allelopathy of mangrove Sonneratia species. Proceedings of the $74^{\text {th }}$ Annual Meeting of the Botanical Society of Japan, p. 222.

Inoue, A., Hasegawa, A., Tsuchiya, S., Minagawa, R., Fujii, Y., \& Sasamoto, H. (2010). Development of bioassay method of allelopathy by Sandwich method and Protoplast method: Leguminosae and Sonneratiaceae. Proceedings of $16^{\text {th }}$ Annual Meeting of Japan mangrove Society, p. 14.

Jorge, M. A., Eilitta, M., Proud, F. J., Maasdorp, B.V., Beksissa, H., Sarial, A. K., \& Hanson, J. (2007). Mucuna species: Recent advances in application of Biotechnology. In Fruit, vegetable and cereal science and biotechnology (pp. 80-94). Global Science Books.

Kao, K. N., \& Michayluk, M. R. (1975). Nutritional requirement for growth of Vicia hajastana cells and protoplasts at a very low population density in liquid media. Planta, 126, 105-110. http://dx.doi.org/10.1007/BF00380613

Murashige, T., \& Skoog, F. (1962). A revised medium for rapid growth and bioassay with tobacco tissue cultures. Physiologia Plantarum, 15, 473-497. http://dx.doi.org/10.1111/j.1399-3054.1962.tb08052.x

Murashige, T., Sasamoto, H., \& Fujii, Y. (2004). Protoplast cultures of leguminous plants containing allelochemicals. Proceedings of the $68^{\text {th }}$ Annual Meeting of the Botanical Society of Japan, p. 178.

Nishio, T., Sato, T., Mori, K., \& Takayanagi, K. (1988). Simple and efficient protoplast culture procedure of lettuce, Lactuca sativa L. Japanese Journal of Breeding, 38, 165-171.

Obata-Sasamoto, H., Nishi, N., \& Komamine, A. (1981). Mechanism of suppression of DOPA accumulation in a callus culture of Stizolobium hassjoo. Plant and Cell Physiology, 22, 827-835.

Obata-Sasamoto, H., \& Komamine, A. (1983). Effect of culture conditions on DOPA accumulation in a callus culture of Stizolobium hassjoo. Planta Medica, 49, 120-123. http://dx.doi.org/10.1055/s-2007-969828

Sasamoto, H., Hosoi, Y., \& Koshioka, M. (1995). Endogenous levels of four plant hormones may affect the culture conditions of poplar protoplasts to regenerate plants. In M. Terzi et al. (Eds.), Current Issues in Plant Molecular and Cellular Biology (pp. 481-486). Dordrecht, The Netherlands: Kluwer. http://dx.doi.org/10.1007/978-94-011-0307-7_66

Sasamoto, H., Kawana, Y., Sato, T., Teramoto, S., \& Fujii, Y. (2006). The development of a bioassay method of allelopathy by using protoplast cultures system: Mucuna vs. lettuce root protoplasts. Proceedings of the $70^{\text {th }}$ Annual Meeting of the Botanical Society of Japan, p. 166.

Sasamoto, H., Murashige-Baba, T., Inoue, A., Sato, T., Hayashi, S., \& Hasegawa, A. (2011). Development of a new bioassay method 'Protoplast method', using protoplast culture system of a leguminous plant, Mucuna pruriens, containing strong allelochemical L-DOPA. In S. Luo et al. (Eds.), Proceedings of the $6^{\text {th }}$ world congress on allelopathy (pp. 86-95). Ghangzhou, China. 
Sasamoto, H., Murashige, T., Kawana, Y., Fukumoto, T., Teramoto, S., \& Fujii, Y. (2005). Protoplast cultures of Mucuna for the development of a bioassay method of allelopathy. Proceedings of the $69^{\text {th }}$ Annual Meeting of the Botanical Society of Japan, p. 146.

Sasamoto, H., Wakita, Y., \& Baba, S. (1997). Effect of high sorbitol conecentration on protoplast isolation from cotyledons of mangroves, Avicennia marina, and A. lanata. Plant Biotechnology, 14(2), 101-104. http://dx.doi.org/10.5511/plantbiotechnology.14.101

Sato, T., Kawana, Y., Teramoto, S., Fujii, Y., \& Sasamoto, H. (2007). Cell fusion of leguminous plant, Mucuna, containing strong allelochemical. Proceedings of the $71^{\text {th }}$ Annual Meeting of the Botanical Society of Japan, p. 231.

Tsuchiya, S., Inoue, A., Hasegawa, A., Kobayashi, Y., Ogita, S., \& Sasamoto, H. (2011). Amino acid analysis in protoplasts of Mucuna pruriens and a mangrove plant, Caesalpinia crista: Contents of allelochemical L-DOPA and their protoplast cultures. Proceedings of the $75^{\text {th }}$ Annual Meeting of the Botanical Society of Japan, p. 225.

\section{Copyrights}

Copyright for this article is retained by the author(s), with first publication rights granted to the journal.

This is an open-access article distributed under the terms and conditions of the Creative Commons Attribution license (http://creativecommons.org/licenses/by/3.0/). 